\title{
Time for the Global Rollout of Endoscopic Lung Volume Reduction
}

\author{
Coenraad F.N. Koegelenberg ${ }^{a}$ Dirk-Jan Slebos ${ }^{d}$ Pallav L. Shah ${ }^{\mathrm{e}}$ \\ Johan Theron $^{\mathrm{a}, \mathrm{b}}$ Keertan Dhedac Brian W. Allwood ${ }^{\mathrm{c}}$ Felix J.F. Herth ${ }^{\mathrm{f}, \mathrm{g}}$ \\ a Division of Pulmonology, Department of Medicine, Stellenbosch University and Tygerberg Academic Hospital, \\ b Panorama Heart and Lung Unit, Panorama Mediclinic, and 'Division of Pulmonology, Department of Medicine, \\ University of Cape Town and Groote Schuur Hospital, Cape Town, South Africa; ${ }^{d}$ Department of Pulmonary \\ Diseases, University of Groningen, University Medical Center Groningen, Groningen, The Netherlands; \\ e Royal Brompton, Harefield NHS Foundation Trust, and Imperial College, London, UK; ${ }^{\mathrm{P}}$ Pulmonology and \\ Critical Care Medicine, Thoraxklinik, University Hospital Heidelberg, and ${ }^{9}$ Translational Lung Research Center \\ Heidelberg (TLRCH), German Center for Lung Research (DZL), Heidelberg, Germany
}

\section{Key Words}

Coils - Emphysema Endoscopic lung volume reduction . Valves

\begin{abstract}
Chronic obstructive pulmonary disease remains one of the most common causes of morbidity and mortality globally. The disease is generally managed with pharmacotherapy, as well as guidance about smoking cessation and pulmonary rehabilitation. Endoscopic lung volume reduction (ELVR) has been proposed for the treatment of advanced emphysema, with the aim of obtaining the same clinical and functional advantages of surgical lung volume reduction whilst potentially reducing risks and costs. There is a growing body of evidence that certain well-defined sub-groups of patients with advanced emphysema may benefit from ELVR, provided the selection criteria are met and a systematic approach is followed. ELVR devices, particularly unidirectional valves and coils, are currently being rolled out to many countries outside of the USA and Europe, although very few centres currently have the capacity to correctly evaluate and provide ELVR to prospective candidates. The high cost of these interventions underpins the need for careful patient selection to
\end{abstract}

best identify those who may or may not benefit from ELVRrelated procedures. The aim of this review is to provide the practicing pulmonologist with an overview of the practical aspects and current evidence for the use of the various techniques available, and to suggest an evidence-based approach for the appropriate use of these devices, particularly in emerging markets, where there should be a drive to develop and equip key specialised ELVR units.

(C) 2015 S. Karger AG, Basel

\section{Introduction}

Chronic obstructive pulmonary disease (COPD) remains one of the most common causes of morbidity and mortality globally [1]. Although smoking is the most common risk factor for the development of COPD, longterm biomass fuel exposure and tuberculosis may contribute to the disease burden in some developing countries [2]. The disease is generally managed with pharmacotherapy, as well as guidance about smoking cessation and pulmonary rehabilitation [3].

Surgical lung volume reduction has been shown to improve clinical and functional status and mortality in the

\section{KARGER 125}

C 2015 S. Karger AG, Basel

0025-7931/15/0905-0430\$39.50/0 
Table 1. Techniques and devices available for ELVR

Bronchial blocking devices

- Unidirectional endobronchial and intrabronchial valves

- Spigots

Parenchymal devices

- Coils

- Sealants

- Vapour

Extra-anatomical bypass

- Airway bypass

sub-group of patients with predominant upper-lobe emphysema and low exercise capacity [4]. Endoscopic lung volume reduction (ELVR) has been proposed as an alternative intervention, with the aim of reducing risks and costs whilst obtaining the same clinical and functional advantages of lung volume reduction [5]. There is a growing body of evidence that certain well-defined sub-groups of patients with advanced emphysema may benefit from ELVR, provided that the selection criteria are met and a systematic approach is followed.

Several techniques (table 1 ) are currently available, but only a few modalities have been properly evaluated in prospective trials. The aim of this review is to provide the practicing pulmonologist with an overview of the practical aspects and current evidence for the use of the various techniques available, and to suggest an evidence-based approach for the appropriate use of these devices, particularly in emerging markets.

\section{The Rationale for Lung Volume Reduction}

A reduced alveolar surface area due to the formation of blebs and bullae and reduced elastic recoil are pathognomonic features of emphysema. Early airway closure occurs during expiration with resultant air trapping and hyperinflation. Consequently, the range of expansion of preserved areas of lung tissue decreases. Moreover, air trapping and hyperinflation place the diaphragm at a mechanical disadvantage due to its flattened configuration [6]. These processes all lead to refractory dyspnoea in patients with advanced emphysema.

ELVR, in principle, aims to achieve volume loss of the targeted region, thereby redirecting airflow to less affected regions [5]. Dynamic hyperinflation decreases, and diaphragm and chest wall mechanics improve. The re- maining lung tissue, in theory, has better elastic properties, which can restore the outward radial pull on the small airways, thereby increasing expiratory airflow. Reducing the inhomogeneity of regional ventilation and perfusion improves ventilation/perfusion matching. Endobronchial coils also re-tension the airway network to mechanically increase elastic recoil in the emphysematous lungs and tether open the airways, thereby preventing airway collapse [7].

\section{Caveats}

Bronchial blocking devices, but not endobronchial coils, have been shown to be less effective in homogeneous emphysema or in cases where significant collateral ventilation is present $[5,8]$. The degree of heterogeneity is generally judged on chest computed tomography (CT) scanning, either by visual inspection or with the aid of specifically designed software. A subjective 4-point tissue destruction score scale $(0-25 \%, 26-50 \%, 51-75 \%$ or $>75 \%$ visible tissue destruction) was previously utilised, and a difference of $>1$ point between ipsilateral lobes was required for the disease to be considered inhomogeneous [8]. A superior method, however, is quantitative analysis of thoracic CT scans by various dedicated software packages (e.g. CIRRUS ${ }^{\circledR}$ Lung or Thirona ${ }^{\circledR}$ ). A difference of $>25 \%$ at -950 Hounsfield units (HU) between ipsilateral upper and lower lobes denotes heterogeneous emphysema [8]. More recently, newer software packages (e.g. VIDA $^{\circledR}$ Apollo software) using high-resolution CT (HRCT) scans have even been developed and tested to perform quantitative measurements at lobar and even segmental levels $[9,10]$.

Collateral ventilation is a normal physiological phenomenon. Significant interlobar collateral ventilation prevents atelectasis and thereby subverts the deflating effect of endobronchial blocking devices. Interlobar collateral ventilation is considered to be present if HRCT scans show incomplete fissures [5]. Most European centres currently use an endobronchial catheter system (Chartis Pulmonary Assessment System ${ }^{\circledR}$, Pulmonx Inc.) to evaluate the presence and percentage of interlobar collateral ventilation. A balloon catheter, connected to a console, is inserted via a bronchoscope into an airway and inflated, thereby occluding the airway and preventing direct outflow of inspired air [11]. A near-constant rate of expiratory airflow during the assessment is seen in cases with collateral ventilation, whereas a steady reduction in flow is observed in the absence of collateral ventilation. A re- 


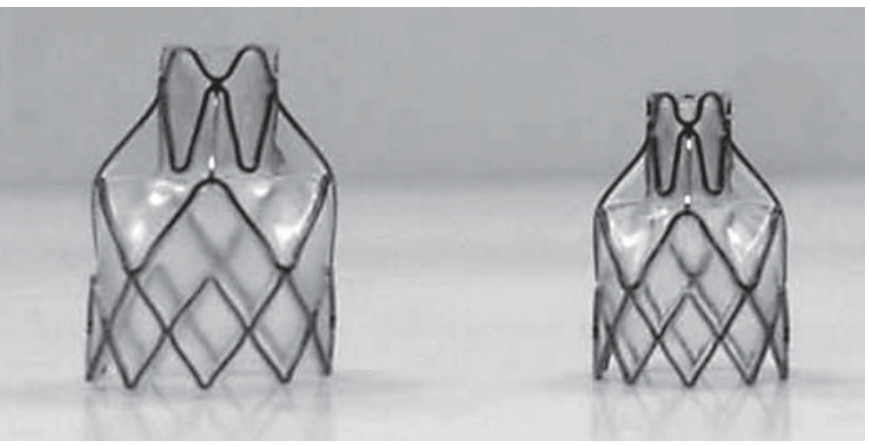

Fig. 1. Endobronchial $\left(\right.$ Zephyr $\left.^{\circledR}\right)$ valves of varying diameters for lobar or segmental occlusion.

cent study found that quantitative HRCT achieved results comparable to those of the Chartis system for the use as a guide to effectively assess collateral ventilation and to select patients for valve-based ELVR procedures [12]. The evidence suggests that if the fissures are $<75 \%$ intact, the Chartis system evaluation should not be performed as collateral ventilation is always present, whereas when they are $>90 \%$ complete, the Chartis evaluation is superfluous as collateral ventilation is practically never present. The Chartis system evaluation is still useful for cases with $75-90 \%$ fissural integrity.

\section{Modalities and Devices}

\section{Unidirectional Endobronchial and \\ Intrabronchial Valves}

Technical Aspects

The most commonly used commercially available devices are the Zephyr ${ }^{\circledR}$ endobronchial valves (EBV; Pulmonx Inc.) and $\mathrm{IBV}^{\circledR}$ intrabronchial valves (Olympus Respiratory America). Both devices are self-expanding and delivered using a catheter that is introduced through the working channel of a flexible bronchoscope [5].

Zephyr valves (fig. 1) are made of a nitinol (nickel titanium) mesh covered by silicone and contain a double silicon membrane within that opens during expiration and closes during inspiration [5]. The valves are available in two sizes: one for segmental $(4.0-9.0 \mathrm{~mm})$ and one for lobar bronchi $(5.5-8.5 \mathrm{~mm})$. Anchorage of the valve to the airway is facilitated by the irregular surface and selfexpanding strength of the mesh.

IBV valves (fig. 2) are umbrella-shaped devices made of a nitinol mesh covered by a polyurethane membrane [5]. The valve is secured to the airway wall by hook-like

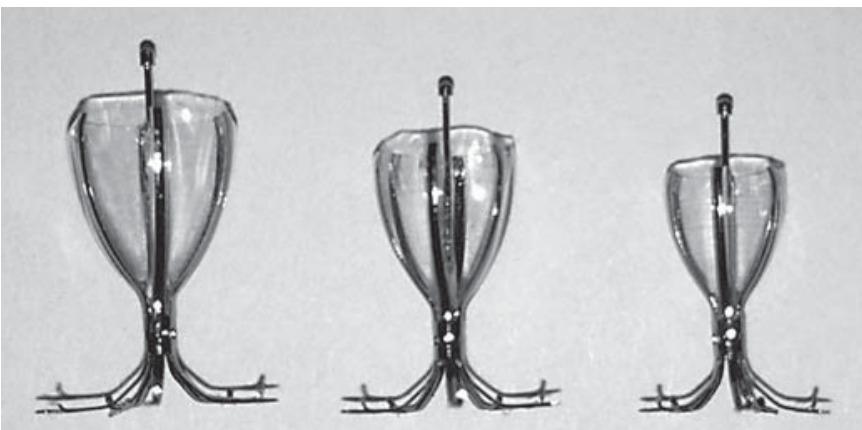

Fig. 2. Intrabronchial $\left(\mathrm{IBV}^{\circledR}\right)$ valves.

anchors and can be removed by pulling on a proximal central rod. It is available in 4 different sizes $(5,6,7$ and 9 $\mathrm{mm}$ ), and airways are sized with a balloon prior to deployment of the valves with the aid of a flexible bronchoscope.

\section{Evidence}

Endobronchial and intrabronchial valves are the most extensively studied devices for ELVR. The initial pilot studies published more than a decade ago showed promising results with regard to safety and improvement in lung function and exercise tolerance, but the results also suggested that further research was needed to identify the patients who would benefit most from the procedure $[13,14]$.

A large randomised multicentre study on the effectiveness and safety of Zephyr valves for the treatment of emphysema (Endobronchial Valve for Emphysema Palliation Trial or VENT) was conducted at 31 centres in the USA, and at 23 in Europe, and a total of 492 patients were enrolled. The patients were randomly assigned $(2: 1)$ to the valve-treatment arm with unilateral lobar volume reduction or the control arm (standard medical care) [15]. Efficacy endpoints were percent changes in forced expiratory volume in $1 \mathrm{~s}\left(\mathrm{FEV}_{1}\right)$ and the 6-min walking distance (6MWD) on an intention-to-treat analysis. At 6 months, the EBV group in the US cohort showed an increase of $4.3 \%$ in the $\mathrm{FEV}_{1}$ (an increase of 1.0 percentage point of the predicted value), compared with a decrease of $2.5 \%$ in the control group [16]. Thus, there was a mean betweengroup difference of $6.8 \%$ in the $\mathrm{FEV}_{1}$ percentage predicted $(\mathrm{p}=0.005)$, which, although statistically significant, was not viewed as clinically meaningfully different. A roughly similar between-group difference was observed for the 6MWD. Of note is the fact that patients with high 
heterogeneity between lobes and intact fissures experienced statistically significant and clinically meaningful improvements in $\mathrm{FEV}_{1}$ (in the order of 13-18\%) and 6MWD (4-7\%) [16]. At 90 days, the EBV group experienced increased rates of exacerbation requiring hospitalisation ( 7.9 vs. $1.1 \%, \mathrm{p}=0.03$ ) and haemoptysis (6.1 vs. $0 \%, p=0.01)$ compared to the control group. The rate of pneumonia in the targeted lobe was $4.2 \%$ at 1 year for the EBV group.

The European cohort of the VENT study demonstrated even greater differences in $\mathrm{FEV}_{1}(7 \pm 20$ vs. $0.5 \pm 19 \%$; $\mathrm{p}=0.67)$ and St George's Respiratory Questionnaire (SGRQ) score ( $-5 \pm 14$ vs. $0.3 \pm 13$ points; $\mathrm{p}=0.047)$, which was sustained at 12 months [11]. The complication rates did not differ significantly. EBV patients with CT scans suggestive of complete fissuring and those with lobar occlusion had a lobar volume reduction of $-80 \pm 30 \%$, and $>50 \%$ met predefined minimal clinical difference thresholds. Unlike the US cohort, the degree of heterogeneity did not correlate with better outcomes.

A European multicentre, blinded, sham-controlled study was performed to assess the safety and effectiveness of bronchial valve therapy using a bilateral upper-lobe treatment approach without the goal of lobar atelectasis [17]. Although the procedure and devices were well tolerated (with no differences in adverse events reported in the treatment and control groups), the investigators concluded that treatment with bronchial valves without complete lobar occlusion in both upper lobes was ineffective in the majority of cases. A single-centre, randomised study performed in Heidelberg, Germany, confirmed that unilateral intrabronchial valve placement with complete occlusion is superior to bilateral partial occlusion [18]. At 30 and 90 days, significant differences were seen in pulmonary function test, 6MWD and SGRQ scores, in favour of unilateral treatment. At 90 days, $\mathrm{FEV}_{1}$ was improved by $21.4 \pm 10.7 \%$ in this group, but not in the bilateral group $(-0.03 \pm 13.9 \%, \mathrm{p}=0.002)$.

The recently completed STELVIO trial provided the strongest evidence for the importance of collateral ventilation in response to ELVR with valves [19]. Dutch investigators randomised 68 patients with severe emphysema on high-resolution chest CT scans with visual estimation of complete or near-complete fissures to endobronchial Zephyr valve treatment (EBV group, $\mathrm{n}=24$ ) or standard medical care (control group, $\mathrm{n}=34$ ). Interlobar collateral ventilation was measured with the Chartis system. The primary outcome measures were change in $\mathrm{FEV}_{1}$, forced vital capacity (FVC) and 6MWD at 6 months. Clinical relevance was assessed relative to the minimal clinically importance difference. At 6 months, the improvement after EBV treatment compared to control was: $\mathrm{FEV}_{1} 22.7 \%$ (95\% CI, 12.2-33.3), FVC $442 \mathrm{ml}$ (215-668), residual volume (RV) -831 ml (-1,101 to -560), 6MWD $106 \mathrm{~m}$ (80133 ) and SGRQ score -14.7 points ( -21.8 to -7.6$)$ (all $\mathrm{p}<$ $0.001)$. Pneumothoraces were observed in $17.6 \%$ of the EBV group.

Current evidence would therefore suggest that appropriate candidates with heterogeneous emphysema and no collateral ventilation benefit from unilateral valve placement with the intention to achieve lobar collapse [18].

\section{Bronchial Plugs/Spigots}

Technical Aspects

Watanabe Spigots ${ }^{\circledR}$ (Novatech) were introduced in 2003 , initially as a potential treatment option for patients with pulmonary fistula and persistent pneumothorax with continuous air leakage [20]. The spigots are currently available in 3 different sizes in Europe (5, 6 and $7 \mathrm{~mm}$ ). They are manufactured from silicon and have a truncated conical shape and lateral studs that facilitate anchorage to the airways.

\section{Evidence}

Despite many reports about the successful treatment of persistent air leaks with endobronchial Watanabe Spigots, evidence for their use in ELVR is lacking. In one small study, 5 out of 7 patients who were treated obtained improvements in quality of life, vital capacity and exercise capacity [21]. Pneumonia is a relatively common complication of this procedure, presumably as a consequence of the inability of secretions to drain past obstructed bronchi. The general use of spigots for ELVR therefore cannot be supported based on the current evidence [5].

\section{Coils}

Technical Aspects

Coils (RePneu ${ }^{\circledR}$, BTG Inc.) are nitinol devices (fig. 3) that have been preformed to a shape that results in parenchymal retraction after deployment [7]. The device is currently available in 3 lengths $(100,125$ and $150 \mathrm{~mm})$ to accommodate differently sized airways. The coils are implanted via a flexible bronchoscope under general anaesthesia or conscious sedation and fluoroscopic guidance using a proprietary delivery system. The airway in the selected segment is identified with a low-stiffness guidewire (under fluoroscopy), after which a catheter is passed over the guidewire and the length of the airway is measured. The guidewire is then removed and a straightened coil is introduced into the distal end of the catheter with a grasp- 


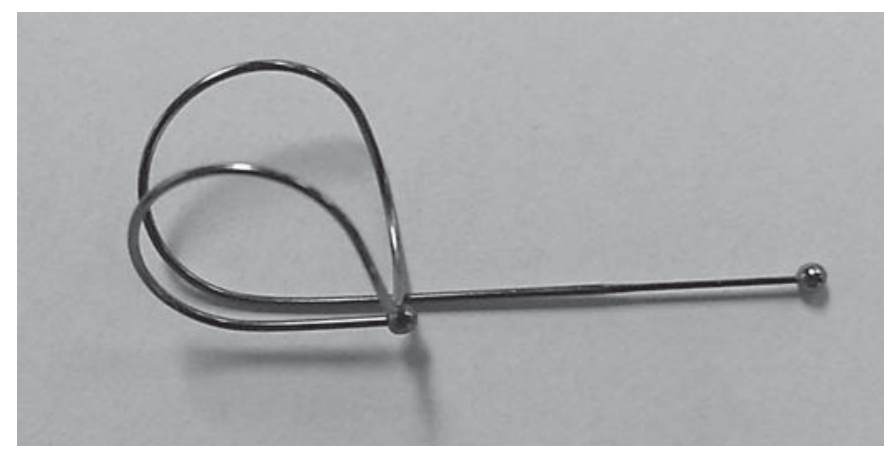

Fig. 3. An endobronchial $\left(\mathrm{RePneu}^{\circledR}\right)$ coil.

er, after which the catheter is removed while the proximal end of the coil is initially advanced and then released, assuming its preformed shape. Coils may be retrieved immediately after deployment and repositioned if needed, but in general, it should be considered an irreversible intervention in the long term (unlike valves).

\section{Evidence}

A pilot study by Herth et al. [7] found ELVR with coils to be safe and feasible. In a subsequent study by Slebos et al. [22], 18 patients with severe heterogeneous disease showed significant improvement in functional parameters. After 6 months, the SGRQ score improved by $14.9 \pm$ 12.1 points (with 11 patients improving by $>4$ points), the $\mathrm{FEV}_{1}$ by a mean of $14.9 \%, \mathrm{FVC}$ by $13.4 \%$, RV by a mean of $11.4 \%$ and $6 \mathrm{MWD}$ by $84.4 \mathrm{~m}$. Adverse events related to either the device or the procedure included pneumothorax $(\mathrm{n}=1)$, pneumonia $(\mathrm{n}=2)$, COPD exacerbation $(\mathrm{n}=6)$, mild chest pain $(\mathrm{n}=4)$ and mild $(<5 \mathrm{ml})$ haemoptysis $(\mathrm{n}=21)$ [22].

In a multicentre study by Shah et al. [23], 47 patients with severe emphysema (both heterogeneous and homogeneous disease) were randomly allocated at a 1:1 ratio to either treatment with coils (treatment group, $\mathrm{n}=23$ ) or best medical care (usual care group, $\mathrm{n}=24$ ). The primary endpoint was the difference in response on the SGRQ between the treatment and the usual care group at 90 days after final treatment (by intention-to-treat analysis). The SGRQ response at 90 days after final treatment was greater in the treatment group than in the usual care group [between-group difference from baseline, -8.36 points (95\% CI, -16.24 to -0.47$) ; \mathrm{p}=0.04$ ] [23]. Moreover, almost $60 \%$ of the treated patients experienced a $>10 \%$ improvement in $\mathrm{FEV}_{1}$. Of significance is the fact that no between-group difference in serious adverse events was observed, suggesting that the bronchoscopy itself rather than the device was to blame for the observed complications.

In the larger multicentre study that initially focussed on mostly heterogeneous disease, 60 patients were treated with coils (55 bilateral) [8]. Safety was evaluated by recording all adverse events. The primary efficacy endpoint was the improvement in SGRQ score from baseline compared with the score at 6 months $(\triangle S G R Q)$. The secondary efficacy endpoints were the comparison between baseline and 6 months for FVC, $\mathrm{FEV}_{1}, \mathrm{RV}, \mathrm{RV}$ /total lung capacity (TLC), improvement in 6MWD and modified Medical Research Council dyspnoea score. At 6 and 12 months, respectively, $\triangle$ SGRQ was $-12.1 \pm 12.9$ and -11.1 \pm 13.3 points, $\triangle 6 \mathrm{MWD}$ was $+29.7 \pm 74.1$ and $+51.4 \pm 76$ $\mathrm{m}, \Delta \mathrm{FEV}_{1}$ was $+0.11 \pm 0.20$ and $+0.11 \pm 0.30$ litres, and $\Delta \mathrm{RV}$ was $-0.65 \pm 0.90$ and $-0.71 \pm 0.81$ litres (all $\mathrm{p}<0.01$ ) [8]. Even more impressive were the high response rates: at 6 months, $48.0 \%$ of the patients were found to have a $\geq 12 \%$ increase in $\mathrm{FEV}_{1}, 64.8 \%$ had a $\geq 0.35$-litre decline in $\mathrm{RV}, 52.8 \%$ a $\geq 26$-metre increase in $6 \mathrm{MWD}$, and $74.1 \%$ a $\geq 4$-point increase in SQRQ score. Post hoc analyses showed significant responses for SGRQ, 6MWD and RV in patients with both heterogeneous and homogeneous emphysema. Serious adverse events that were observed within 30 days of treatment included 7 exacerbations (6.1\%), 6 pneumonias (5.2\%), 4 pneumothoraces (3.5\%) and 1 haemoptysis $(0.9 \%)$. A limitation of this study was the lack of a control group.

An open-label study focussed exclusively on the use of coils in homogeneous emphysema [24]. Ten patients with severe COPD and hyperinflation were treated with a median of 11 coils (range, 10-12) in each lung. At 6 months, 6MWD improved from 289 to $350 \mathrm{~m}(\mathrm{p}=0.005), \mathrm{FVC}$ from 2.17 to 2.55 litres $(\mathrm{p}=0.047)$ and RV from 5.04 to 4.44 litres $(\mathrm{p}=0.007)$ and the SGRQ score decreased from 63 to 48 points $(\mathrm{p}=0.028)$. Similar to the previous study, the response rates for clinically significant improvements in RV, 6MWD and SGRQ score varied from 70 to $80 \%$. Two exacerbations and 1 small pneumothorax were recorded as serious adverse events [24].

Hartman et al. [25] recently reported their 3-year follow-up data on 38 patients who underwent ELVR using coils. The data showed that the coil treatment was safe, with no late pneumothoraces, coil migrations or unexpected adverse events. Although the clinical benefit gradually declined over time, at 3 years after treatment, around $50 \%$ of the patients maintained an improvement in 6MWD and SGRQ and dyspnoea scores [25].

Current evidence would therefore suggest that both appropriate candidates with heterogeneous and those 
with homogeneous emphysema could experience clinically significant benefits from ELVR using coils, irrespective of collateral ventilation or complete lobar collapse.

\section{Other Devices/Techniques}

Sealants

First-generation products used were biological substances aimed at obtaining atelectasis and subsequent fibrosis of the lung parenchyma [5]. At least 1 study reported a modest benefit after 6 months in patients treated with high-dose hydrogel (20 $\mathrm{ml}$ per sub-segment) [26]. Biological substances have now been replaced by synthetic polymeric foam (Aeris Therapeutics). The foam flows into the peripheral airways and acts as a glue that seals the target regions with consequent atelectasis [5]. The AeriSeal ${ }^{\circledR}$ system was evaluated in a multicentre study in Germany [27]. Treatment was well tolerated, even if the efficacy responses were better among Global Initiative for Chronic Obstructive Lung Disease (GOLD) stage III patients $\left[\Delta \mathrm{RV} / \mathrm{TLC}-7.4 \pm 10.3 \% ; \Delta \mathrm{FEV}_{1}+15.9 \pm 22.6 \%\right.$; $\triangle \mathrm{FVC}+24.1 \pm 22.7 \%$; difference in carbon monoxide diffusing capacity $(\triangle \mathrm{DLCO})+19.3 \pm 34.8 \%$; $\triangle 6 \mathrm{MWD}+28.7$ $\pm 59.6 \mathrm{~m} ; \Delta$ SGRQ score $-9.9 \pm 15.3$ points] compared with patients with GOLD stage IV $(\triangle \mathrm{RV} / \mathrm{TLC}-0.5 \pm$ $6.4 \% ; \Delta \mathrm{FEV}_{1}+2.3 \pm 12.3 \% ; \Delta \mathrm{FVC}+2.6 \pm 21.1 \% ; \Delta \mathrm{DLCO}$ $-2.8 \pm 17.2 \% ; \Delta 6 \mathrm{MWD}+28.3 \pm 58.4 \mathrm{~m} ; \Delta$ SGRQ score $-6.7 \pm 7.0$ points). A very recent multicentre, randomised, controlled trial, which was terminated early, confirmed significant improvements in lung function, dyspnoea and quality of life from baseline when compared to controls at 3 months [28]. The improvements persisted at 6 months, with $>50 \%$ of the treated patients experiencing clinically meaningful improvements, while $44 \%$ of the treated patients experienced adverse events requiring hospitalisation (2.5-fold more than among the controls, $\mathrm{p}=0.01$ ), with 2 deaths in the treated cohort.

\section{Vapour}

Bronchoscopic thermal vapour ablation (InterVapor ${ }^{\circledR}$, Uptake Medical) uses high-temperature water vapour delivered into the target lung segments through a catheter with a precise amount of energy, thereby inducing thermal damage and an inflammatory reaction resulting in permanent airway fibrosis [5]. An initial pilot study that included 11 patients with severe heterogeneous emphysema found a modest improvement at the cost of excess serious adverse events, including 5 cases of probable bacterial pneumonia and 2 cases of COPD exacerbation [29]. In a larger study in patients with heterogeneous upperlobe emphysema, a higher dose of vapour was adminis-

Time for the Global Rollout of

Endoscopic Lung Volume Reduction tered [30]. More significant functional changes were observed. A subsequent study also found that lobar fissure integrity had no or minimal influence on improvements in clinical outcomes [31]. Adverse events were frequent in both studies, and at least 1 patient died secondary to a COPD exacerbation. One potential advantage of this technology is that it is not influenced by interlobar collateral ventilation [9].

\section{Airway Bypass}

The technique of airway bypass is based on the creation of extra-anatomic passages between the hyperinflated lung parenchyma and larger airways, with the aim of facilitating expiration and thereby decreasing air trapping [5]. Current evidence suggests that although some short-term benefit may be achieved in patients with severe hyperinflation, the trend is for pulmonary functions to return to baseline over time [32-34]. Moreover, at least 1 death has been reported in the preliminary studies [33].

\section{Evidence-Based Approach to ELVR}

\section{Evaluation}

Current evidence suggests that not all classes and phenotypes of emphysema will benefit from ELVR, and that each technique appears to provide a greater benefit to specific sub-groups of patients [5]. The high cost of these interventions makes careful patient selection imperative to prevent insertion in patients unlikely to gain clinical benefits as well as wasteful expenditure. An ongoing study in France is likely to soon provide information on the cost-effectiveness of ELVR with coils compared to other strategies [35].

The initial screening for suitable candidates should be performed at the pulmonologist level on patients with stable disease and no recent exacerbations. The initial evaluation should include a thorough history (focussing on the level of dyspnoea, functional impairment, past thoracic surgery, comorbidities and smoking status) and physical examination. Routine special investigations should include an HRCT (to estimate heterogeneity, fissure integrity, the degree of tissue destruction and possible underlying lung cancer), full pulmonary function testing (including measurements of $\mathrm{FEV}_{1}, \mathrm{FVC}, \mathrm{RV}, \mathrm{RV} /$ TLC, TLC, DLCO and 6MWD), arterial blood gas and echocardiography (to exclude pulmonary hypertension $>50 \mathrm{~mm} \mathrm{Hg}$ ). The general indications for and contra-indications to valves and coils are summarised in table 2 . ELVR should not be offered to active smokers; patients 
with pulmonary hypertension, unstable cardiac pathology, active respiratory infections or a very poor exercise tolerance; patients with no clear evidence of hyperinflation, and patients who are on any type of antiplatelet or anticoagulant therapy which cannot be stopped for 7 days prior to the procedure.

Appropriate or borderline candidates should be referred to a centre with the capacity to evaluate, treat and follow up these candidates, including the management of complications and removal of devices, if required. These centres should individualise the interventions based on disease phenotypes (e.g. heterogeneous vs. homogeneous disease), the degree of tissue destruction, the presence of collateral ventilation and pulmonary impairment.

In patients with heterogeneous disease it is paramount for ELVR to target and treat the most diseased regions of the lung while preserving the less diseased functional regions [9]. Identification and determination of the severity of emphysema should ideally be performed by computerised analysis of HRCT scans utilising the so-called heterogeneity score or index. The heterogeneity score is calculated from the quantitative analysis of scans using software that detects and measures the percent difference at $-950 \mathrm{HU}$ (using CT slices of $\leq 1 \mathrm{~mm}$ ) between ipsilateral upper and lower lobes [8]. A minimum difference of $15 \%$ is generally required to consider ELVR with valves [11]. The heterogeneity index is calculated as the quantitative measure of the upper-lobe region divided by the quantitative measure of the lower-lobe region [9]. A value of 1 denotes homogeneous disease, whereas high values $(>1)$ indicate upper-lobe predominance. These measurements can also be performed at a segmental level and combined with the tissue-to-air ratio to 'map out' the lung with regard to heterogeneity [9]. This 'targeting' approach is currently being tested in the STEP-UP trial [9].

Two other selection criteria for ELVR with valves are generally used in everyday practice: the low-attenuation area percentage and the fissure integrity score. The lowattenuation area percentage filters subjects with mild-tomoderate disease who are unlikely to benefit from ELVR, and $40 \%$ is generally a minimum requirement $[11,12]$. The fissure integrity score is in essence a surrogate for collateral ventilation, and a score of $90 \%$ is currently used to separate patients with completed fissures from those with incomplete fissures [12]. A recent study by Schuhmann et al. [12], however, suggests that a quantitative CT model provides accuracy, specificity and sensitivity values similar to those of the Chartis system. Both fissure integrity and homogeneity are, of course, irrelevant in the evaluation of patients for ELVR with coils [5].
Table 2. General indications for and contra-indications to ELVR with endobronchial and intrabronchial valves and coils in patients with stable emphysema

\section{Indications}

- $40-75$ years

- Heterogeneous emphysema and no collateral ventilation (valves) $^{\mathrm{a}}$

- Dyspnoea despite maximal medical therapy and pulmonary rehabilitation

- $\mathrm{FEV}_{1}$ 15-45\%

- Hyperinflation with TLC $>100 \%$ and RV $>150-175 \%$

- $\mathrm{PaCO}_{2}<6.7 \mathrm{kPa}(50 \mathrm{~mm} \mathrm{Hg})$

- $\mathrm{PaO}_{2}>6 \mathrm{kPa}$ (45 mm Hg) while breathing ambient air $6 \mathrm{MWD} \geq 140 \mathrm{~m}$ (after rehabilitation)

Contraindications

- Homogeneous emphysema (valves) ${ }^{\mathrm{a}}$

- Collateral ventilation/non-intact fissures (valves) ${ }^{\mathrm{a}}$

- $\quad>75 \%$ parenchymal destruction on HRCT (coils) ${ }^{\mathrm{b}}$

- Current smoking (previous 6 months)

- DLCO $<20 \%$ (relative contraindication)

- Giant bullae ( $>1 / 3$ of hemithorax)

- $a_{1}$-Antitrypsin deficiency

- Previous thoracotomy, pleurodesis or chest wall deformity

- Excessive sputum

- Severe pulmonary hypertension (>50 mm Hg)

- Active infection

- Unstable cardiac conditions

- Significant pleural or interstitial changes on HRCT

- Any type of antiplatelet or anticoagulant therapy which cannot be stopped for 7 days prior to the procedure

$\mathrm{PaCO}_{2}=$ Partial pressure of carbon dioxide; $\mathrm{PaO}_{2}=$ partial pressure of oxygen.

${ }^{\text {a }}$ Specific for endobronchial and intrabronchial valves.

${ }^{\mathrm{b}}$ Specific for endobronchial coils.

Table 3. General practical issues: unidirectional valves versus coils

\begin{tabular}{|c|c|c|}
\hline & Valves & Coils \\
\hline Extent of emphysema & Heterogeneous & $\begin{array}{l}\text { Hetero-/ } \\
\text { homogeneous }\end{array}$ \\
\hline Useful in $>75 \%$ destruction & Tested & Contra-indicated \\
\hline Collateral ventilation & Contra-indicated & Not relevant \\
\hline Intact fissures & Prerequisite & Not relevant \\
\hline Sides treated & Unilateral & Uni-/bilateral \\
\hline Complete lobar collapse & Required & Not relevant \\
\hline Placement & Sensitive & Insensitive \\
\hline
\end{tabular}

\section{Examples of Current Approaches}

There is currently no head-to-head evidence comparing the various techniques and devices, and no official guideline from any of the major thoracic societies. The 


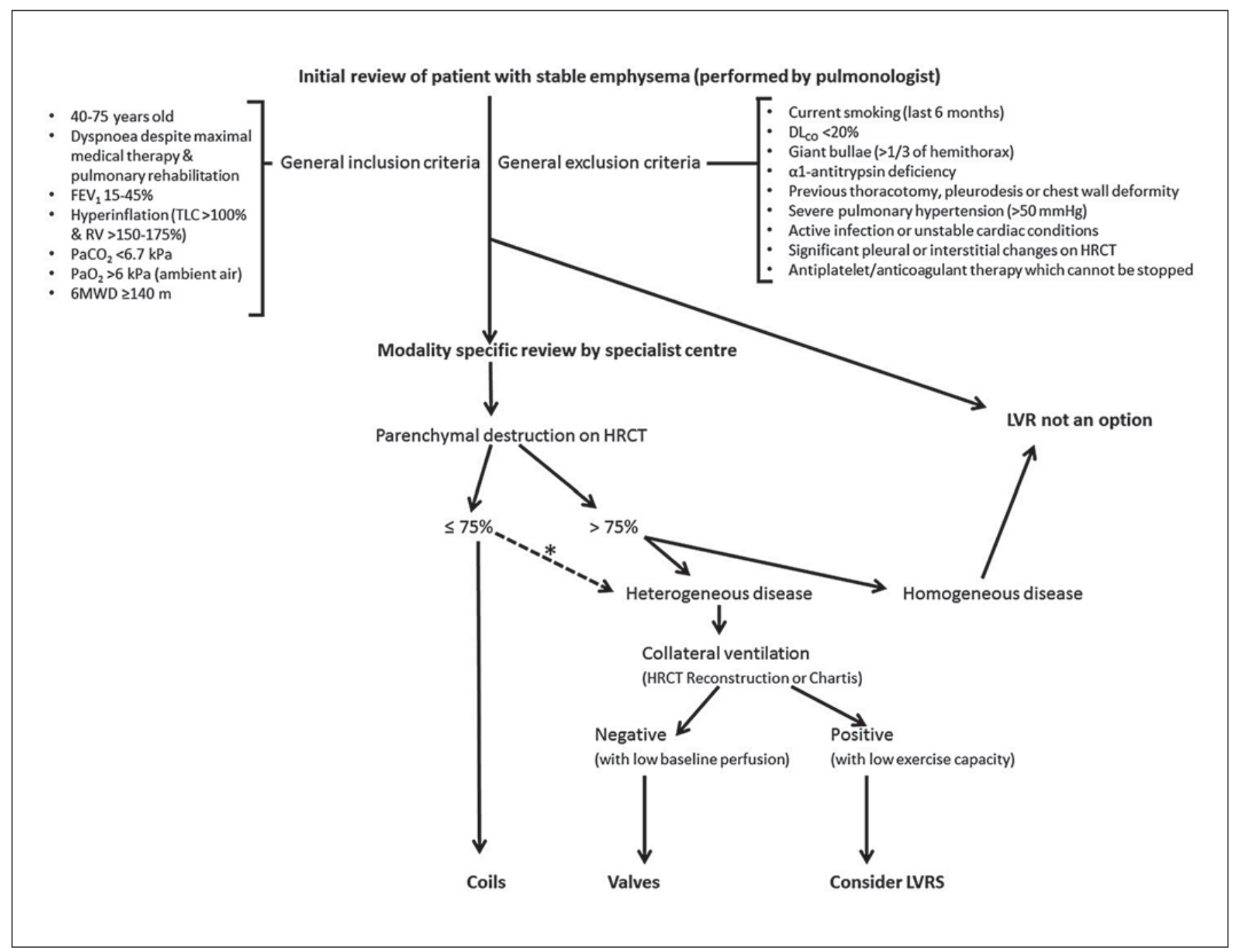

Fig. 4. One example of a general approach to ELVR in a centre with access to only valves and coils (endorsed by the Assembly on Interventional Pulmonology of the South African Thoracic Society). * Patients with $25-75 \%$ of tissue destruction and no co-lateral circulation may also benefit from valves, although the reported re-

main differences between unidirectional valves and coils are summarised in table 3 . Some guidelines do exist, but most are institutional or centre-specific rather than rigorously tested and evidence-based position statements. It is recommended that all ELVR procedures should be performed in the context of a local and/or international registry.

One example of a general approach to ELVR in a centre with access to valves and coils is provided in figure 4 . Another approach followed in a very experienced centre (University Medical Center Groningen, Groningen, The sponse rates and improvements in functional status and pulmonary function test seem to favour ELVR with coils. LVR = Lung volume reduction; LVRS = lung volume reduction surgery; $\mathrm{PaCO}_{2}=$ partial pressure of carbon dioxide; $\mathrm{PaO}_{2}=$ partial pressure of oxygen.

Netherlands) with access to practically all interventions is summarised in figure 5.

The degree of tissue destruction/severity of emphysema (fig. 6), heterogeneity of the disease and the presence of collateral ventilation are crucial in the final evaluation and selection process [5]. The algorithm should, however, not be seen as a rigid guide, as some patients may benefit from either coils or valves. Patients with $25-75 \%$ of tissue destruction and no collateral ventilation may, for example, also benefit from valves, although the reported response rates and improvements in functional status and 
Fig. 5. An example of a general approach to ELVR in an experienced centre with access to all devices. LVRS = Lung volume reduction surgery.
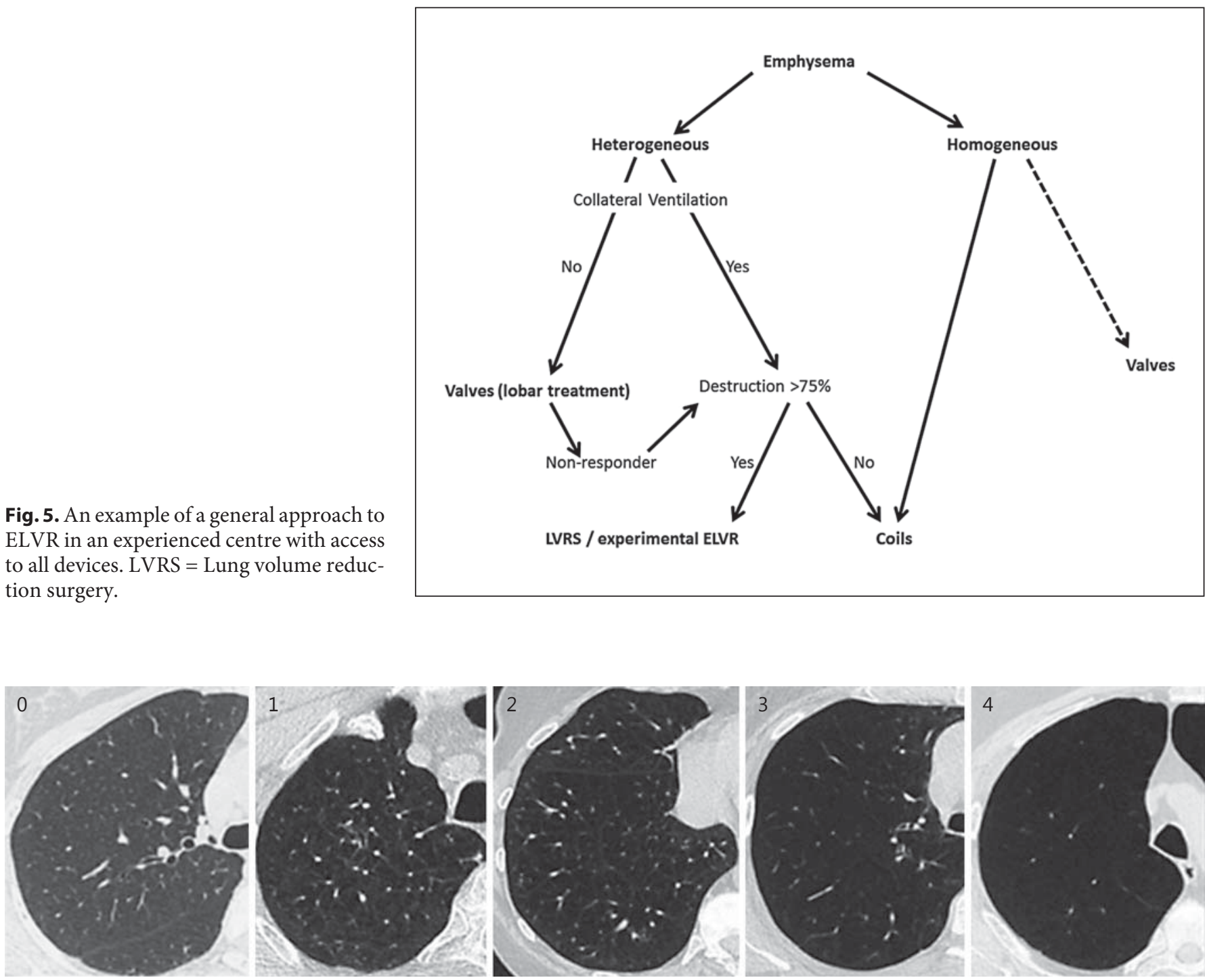

Fig. 6. The degree of tissue destruction as a guide to device selection. Patients with visual scores of $0-3$ can be considered for ELVR with coils, whereas those with scores of 2-4 may be suited for ELVR with valves (provided collateral ventilation is excluded).

pulmonary function test results seem to be greater with coils $[7-9,16,19]$. Many centres currently favour the use of valves in this setting, given the greater body of prospective evidence for its use [5]. Generally speaking, however, patients with a high degree of hyperinflation with relatively preserved lung parenchyma are more likely to benefit from ELVR with bilateral coils, starting with the more affected side (irrespective of the collateral ventilation and heterogeneity of the disease) $[8,24]$, whereas patients with heterogeneous disease, no collateral circulation and a low baseline perfusion (on ventilation/perfusion scan- ning) benefit from unilateral therapy with the goal to achieve lobar collapse $[11,16,18]$.

It should be highlighted that the evidence for ELVR has been accumulated from patients with emphysema and hyperinflation related primarily to cigarette smoking in the developed world, without the presence of comorbid lung disease. The local burden of disease should be considered when planning to initiate an EVLR program in other settings, as these results may not be applicable to subjects with different or co-morbid causes of hyperinflation (e.g. bronchiectasis). 


\section{Conclusions}

Current evidence suggests that in well-defined subgroups of patients with severe emphysema ELVR may be of benefit. A well-structured approach to ELVR, including initial screening and subsequent referral to a specialised centre is important to ensure against inappropriate use of devices, which may be both wasteful and harmful.

Patients with a high degree of hyperinflation and relatively preserved lung parenchyma are more likely to benefit from ELVR using bilateral coils (irrespective of the collateral circulation and heterogeneity of the disease), whereas patients with heterogeneous disease, no collateral circulation and a low baseline perfusion may benefit from unilateral ELVR using valves with the goal of achieving lobar collapse. The exact utility of ELVR with valves and/or coils in homogeneous disease or the use of other devices, particularly sealants, is still being investigated.
Moreover, there are currently numerous ongoing trials, and the suggested approaches are likely to be refined during the next decade.

Internationally there should be a drive to develop and equip certain key specialised ELVR units within various health care systems and regions. The bare minimum skills required for such units would include the ability to assess patients in a manner outlined in this document, and the technical skills to perform ELVR with both valves and coils.

\section{Financial Disclosure and Conflicts of Interest}

C.F.N. Koegelenberg, J. Theron, K. Dheda, B.W. Allwood and P.L. Shah have nothing to declare. F.J.F. Herth and D.-J. Slebos have performed consultant work for PneumRx, Uptake Medical and Aeris OthO.

\section{References}

1 Lopez A, Shibuya K, Rao C, et al: Chronic obstructive pulmonary disease: current burden and future projections. Eur Respir J 2006;27: 297-412.

2 Allwood B, Myer L, Bateman E: A systematic review of the association between pulmonary tuberculosis and the development of chronic airflow obstruction in adults. Respiration 2013;86:76-85.

3 Global Initiative for Chronic Obstructive Lung Disease: Global Strategy for Diagnosis, Management, and Prevention of COPD. 2015. http://www.goldcopd.org/guidelinesglobal-strategy-for-diagnosis-management. html.

4 Fishman A, Martinez F, Naunheim K, et al; National Emphysema Treatment Trial Group: A randomized trial comparing lungvolume-reduction surgery with medical therapy for severe emphysema. N Engl J Med 2003;348:2059-2073.

5 Gasparini S, Zuccatosta L, Bonifazi M, Bolliger CT: Bronchoscopic treatment of emphysema: state of the art. Respiration 2012;84: 250-263.

-6 McDonough J, Yuan R, Suzuki M, et al: SmallAirway Obstruction and Emphysema in chronic obstructive pulmonary disease. $\mathrm{N}$ Engl J Med 2011;365:1567-1575.

-7 Herth FJF, Eberhard R, Gompelmann D, Slebos D-J, Ernst A: Bronchoscopic lung volume reduction with a dedicated coil: a clinical pilot study. Ther Adv Respir Dis 2010;4:225231.

8 Deslee G, Klooster K, Hetzel M, et al: Lung volume reduction coil treatment for patients with severe emphysema: a European multicentre trial. Thorax 2014;69:980-986.

-9 Bandyopadhyay S, Henne E, Gupta A, et al: Segmental approach to lung volume reduction therapy for emphysema patients. Respiration 2015;89:76-81.

10 Gietema H, Müller N, Fauerbach P, et al: Quantifying the extent of emphysema: factors associated with radiologists' estimations and quantitative indices of emphysema severity using the ECLIPSE cohort. Acad Radiol 2011; 18:661-671.

11 Herth FJF, Noppen M, Valipour A, et al: Efficacy predictors of lung volume reduction with Zephyr valves in a European cohort. Eur Respir J 2012;39:1334-1342.

12 Schuhmann M, Raffy P, Yin Y, et al: CT predictors of response to endobronchial valve lung reduction treatment: comparison with Chartis. Am J Respir Crit Care Med 2015;191: 767-774.

13 Snell G, Holsworth L, Borrill Z, et al: The potential for bronchoscopic lung volume reduction using bronchial prostheses: a pilot study. Chest 2003;124:1073-1080.

14 Toma T, Hopkinson N, Hillier J, et al: Bronchoscopic volume reduction with valve implants in patients with severe emphysema. Lancet 2003;361:931-933.

15 Strange C, Herth F, Kovitz K, et al: Design of the Endobronchial Valve for Emphysema Palliation Trial (VENT): a non-surgical method of lung volume reduction. BMC Pulm Med 2007;7:10.

16 Sciurba FC, Ernst A, Herth FJF, et al: A randomized study of endobronchial valves for advanced emphysema. N Engl J Med 2010; 363:1233-1244.

17 Ninane V, Geltner C, Bezzi M, et al: Multicentre European study for the treatment of advanced emphysema with bronchial valves. Eur Respir J 2012;39:1319-1325.

18 Eberhardt R, Gompelmann D, Schuhmann $\mathrm{M}$, et al: Complete unilateral vs partial bilateral endoscopic lung volume reduction in patients with bilateral lung emphysema. Chest 2012;142:900-908.

19 Klooster K, ten Hacken N, Hartman J, Kerstjens H, van Rikxoort E, Slebos D-J: Endobronchial valve treatment versus standard medical care in patients with emphysema without interlobar collateral ventilation (the STELVIO trial). Am J Respir Crit Care Med 2015;191:A6312.

20 Watanabe Y, Matsuo K, Tamaoki A, Komoto R, Hiraki S: Bronchial occlusion with endobronchial Watanabe Spigot. J Bronchol 2003; 10:264-267.

21 Toma T, Matsuo K, Tamaoki A: Endoscopic bronchial occlusion with spigots in patients with emphysema. Am J Respir Crit Care Med 2002;165:B9.

22 Slebos D-J, Klooster K, Ernst A, Herth FJF, Kerstjens HM: Bronchoscopic lung volume reduction coil treatment of patients with severe heterogeneous emphysema. Chest 2012; 142:574-582.

23 Shah PL, Zoumot Z, Singh S, et al: Endobronchial coils for the treatment of severe emphysema with hyperinflation (RESET): a randomised controlled trial. Lancet Respir Med 2013;1:233-240.
Time for the Global Rollout of

Endoscopic Lung Volume Reduction 
24 Klooster K, ten Hacken NHT, Franz I, Kerstjens HM, van Rikxoort EM, Slebos D-J: Lung volume reduction coil treatment in chronic obstructive pulmonary disease patients with homogeneous emphysema: a prospective feasibility trial. Respiration 2014;88:116-125.

25 Hartman J, Klooster K, Gortzak K, ten Hacken N, Slebos D-J: Long-term follow-up after bronchoscopic lung volume reduction treatment with coils in patients with severe emphysema. Respirology 2015;20:319-326.

26 Criner G, Pinto-Plata V, Strange C, et al: Biologic lung volume reduction in advanced upper lobe emphysema: phase 2 results. Am J Respir Crit Care Med 2009;179:791-798.

$\checkmark 27$ Herth F, Gompelmann D, Stanzel F, et al: Treatment of advanced emphysema with emphysematous lung sealant $\left(\right.$ AeriSeal ${ }^{\circledR}$ ). Respiration 2011;82:36-45.
28 Come C, Kramer M, Dransfield M, et al: A randomised trial of lung sealant versus medical therapy for advanced emphysema. Eur Respir J 2015;46:651-662.

29 Snell G, Hopkins P, Westall G, Holsworth L, Carle A, Williams T: A feasibility and safety study of bronchoscopic thermal vapor ablation: a novel emphysema therapy. Ann Thorac Surg 2009;88:1993-1998.

30 Snell G, Herth F, Hopkins P, et al: Bronchoscopic thermal vapour ablation therapy in the management of heterogeneous emphysema. Eur Respir J 2012;39:1326-1333.

31 Gompelmann D, Heussel C, Eberhardt R, et al: Efficacy of bronchoscopic thermal vapor ablation and lobar fissure completeness in patients with heterogeneous emphysema. Respiration 2012;83:400-406.
Choong C, Macklem P, Pierce J, et al: Airway bypass improves the mechanical properties of explanted emphysematous lungs. Am J Respir Crit Care Med 2008;178:902-905.

33 Cardoso P, Snell G, Hopkins P, et al: Clinical application of airway bypass with paclitaxeleluting stents: early results. J Thorac Cardiovasc Surg 2007;134:974-981.

-34 Shah P, Slebos D-J, Cardoso P, et al: Bronchoscopic lung-volume reduction with Exhale airway stents for emphysema (EASE trial): randomised, sham-controlled, multicentre trial. Lancet 2011;378:997-1005.

35 Deslee G, Barbe C, Bourdin A, et al: Costeffectiveness of lung volume reduction coil treatment in emphysema. STIC REVOLENS (in French). Rev Mal Respir 2012;29:11571164. 